\title{
Sistem Pengaduan Masyarakat dan Tindak Lanjut Terintegrasi Layanan Publik Menuju Percepatan E-Government (Studi Kasus Provinsi Sulawesi Tenggara)
}

\author{
Wahyu Ramadhan \\ Bumigora University \\ Wahyurama24@gmail.com
}

\begin{abstract}
Abstrak - Tata Kelola Pemerintahan adalah Terwujudnya suatu model kepemerintahan yang baik dan bertanggungjawab atau good governance merupakan prasyarat bagi setiap pemerintahan untuk mewujudkan aspirasi masyarakat dalam mencapai tujuan serta cita-cita berbangsa dan bernegara. Terkait dengan upaya tersebut diperlukan pengembangan dan penerapan suatu sistem monitoring dan laporan pertanggungjawaban instansi pemerintah yang tepat, jelas, terukur dan legitimate sehingga penyelenggaraan pemerintahan dan pelaksanaan pembangunan dapat berlangsung secara berdayaguna, berhasilguna, bersih dan bertanggungjawab. Keberhasilan pembangunan di suatu wilayah sangat tergantung dari peran aktif masyarakatnya, serta adanya hubungan yang harmonis antara pemerintah daerah dan masyarakat. Sinergi antara masyarakat dengan pemerintah daerah akan memaksimalkan potensi suatu wilayah dan berdampak pada kemajuan daerah tersebut. Dengan membuat layanan website dan aplikasi pengaduan akan menjadi 'jembatan penghubung' antara masingmasing organisasi perangkat daerah dengan pimpinan daerah maupun antara masyarakat dan Pemerintah Daerah guna mendapatkan pelayanan informasi public yang akurat, efektif, efisien dan dapat dipertanggungjawabkan.
\end{abstract}

Kata Kunci: Web, Android, Sistem Pengaduan, Python, MySQL.

\section{LATAR BELAKANG}

Bergulirnya Reformasi dalam Negara Kesatuan Republik Indonesia membawa perubahan dalam Sistem Pemerintahan Negara ditandai dengan adanya tuntutan tata kelola kepemerintahan yang baik (Good Governance) yang mensyaratkan ditetapkannya prinsip-prinsip akuntabilitas, transparansi dan partisipasi masyarakat dalam setiap proses kebijakan publik. Idealnya Tata Kelola Pemerintahan adalah Terwujudnya suatu model kepemerintahan yang baik dan bertanggungjawab atau good governance merupakan prasyarat bagi setiap pemerintahan untuk mewujudkan aspirasi masyarakat dalam mencapai tujuan serta cita-cita berbangsa dan bernegara. Terkait dengan upaya tersebut diperlukan pengembangan dan penerapan suatu sistem monitoring dan laporan pertanggungjawaban instansi pemerintah yang tepat, jelas, terukur dan legitimate sehingga penyelenggaraan pemerintahan dan pelaksanaan pembangunan dapat berlangsung secara berdayaguna, berhasilguna, bersih dan bertanggungjawab[1].

Kita ketahui, bahwa Pemerintah Provinsi Sulawesi Tenggara adalah salah satu pemerintah daerah penerima Program Hibah Jalan Daerah untuk mendukung pemeliharaan jalan daerah. Untuk itu Melalui Forum LLAJ saat ini membangun dan mengembangkan Sistem Teknologi Informasi dengan model e-Government sebagai pendukung Pelaksanaan program untuk monitoring, informasi dan pengaduan untuk masyarakat. Hal ini dibarengi dengan hadirnya e-
Government tentunya akan melahirkan sebuah pemerintahan yang efesien, efektif dan memiliki tingkat produktivitas yang tinggi serta transparan, dimana untuk semua itu peranan Teknologi Informasi adalah sebagai modal utama. Baik itu infrastruktur, sumber daya manusia maupun sistem aplikasi yang dikembangkan.

Perkembangan teknologi informasi dalam era sekarang ini menghadirkan suatu permasalahan baru dimana keberadaan website dan Aplikasi Pelaporan dipandang perlu segera dilakukan update agar lebih kompatibel dengan kemajuan teknologi komunikasi dan informatika yang cukup pesat saat-saat ini. Masyarakat lebih senang dalam menggunakan smartphone atau telepon pintar dalam aktivitas mereka sehari-hari[2].

Perangkat ini dapat digunakan dengan mudah oleh berbagai kalangan, mulai dari anak-anak, remaja, hingga orang tua karena caranya yang sangat mudah, user friendly,interaksi yang menarik. Bahkan smartphone juga menjadi media yang efektif untuk penyebarluasan informasi. Keberhasilan pembangunan di suatu wilayah sangat tergantung dari peran aktif masyarakatnya, serta adanya hubungan yang harmonis antara pemerintah daerah dan masyarakat. Sinergi antara masyarakat dengan pemerintah daerah akan memaksimalkan potensi suatu wilayah dan berdampak pada kemajuan daerah tersebut[3].

Dengan membuat layanan website dan aplikasi pengaduan akan menjadi 'jembatan penghubung' antara masing-masing organisasi perangkat daerah

Sistem Pengaduan Masyarakat dan Tindak Lanjut Terintegrasi Layanan Publik Menuju Percepatan E-Government (Studi Kasus Provinsi Sulawesi Tenggara) 
dengan pimpinan daerah maupun antara masyarakat dan Pemerintah Daerah guna mendapatkan pelayanan informasi public yang akurat, efektif, efisien dan dapat dipertanggungjawabkan.

Pemerintah Daerah bisa dengan mudah memahami persoalan yang ada di masyarakat dan masyarakat bisa mendapat pelayanan yang cepat dan baik. Keluhan atau usulan masyarakat dengan cepat didengar Pemerintah Daerah dan tentunya Pemerintah Daerah beserta jajarannya lebih mudah melakukan pekerjaannya karena problemnya jelas dan siapa yang bertanggung jawab untuk menyelesaikan masalah juga jelas. Evaluasi untuk kinerja masing-masing OPD lebih mudah dilakukan dan tidak ada lagi saling lempar kesalahan. Tentunya ini akan memudahkan tugas Gubernur untuk melayani masyarakatnya tanpa dibatasi waktu dan jarak.

\section{LANDASAN TEORI}

\section{A. Internet}

Perkembangan teknologi sekarang ini telah melahirkan sumber daya informasi yang tidak dibatasi oleh ruang dan waktu. Sumber daya informasi tersebut adalah internet. Internet dapat memberikan informasi yang kita butuhkan. Penemuan internet telah menjadikan solusi dimana individu-individu maupun organisasi yang ada dapat berkomunikasi dengan mudah. Namun ada sisi buruk internet sendiri yang merupakan sarana atau media global untuk segala segala apa yang ada di dunia ini baik dalam bentuk kejahatan maupun kebaikan. Di samping itu tentunya pornografi yang semakin menjamur dan sulit dibendung telah memasuki media internet. Internet adalah metode yang menghubungkan berbagai komputer ke dalam satu jaringan komputer global, melalui protokol yang disebut TCP/IP (Transmission Control Protocol/Internet Protocol). Protokol adalah suatu petunjuk yang menggunakan pekerjaan yang akan user lakukan dengan internet, apakah akan mengakses website, melakukan transfer file mengirim e-mail dan sebagainya. Protokol dapat dibayangkan seperti suatu bahasa yang digunakan untuk berkomunikasi berbagai jenis komputer maupun sistem operasi yang terhubung di internet[4].

\section{B. Python}

Python merupakan bahasa pemrograman yang berorientasi objek dinamis yang dapat digunakan untuk bermacam-macam pengembangan perangkat lunak seperti yang dapat kita lihat pada sumber http://www.python.org/about/apps. Python menyediakan dukungan yang kuat untuk integrasi dengan bahasa pemrograman lain dan alat-alat bantunya. Python hadir dengan pustaka-pustaka standar yang dapat diperluas serta dapat dipelajari hanya dalam beberapa hari. Python meningkatkan kualitas pengembangan karena kode sumber yang mereka tulis dapat terus dipelihara[5].

Python dapat berjalan dibanyak platform/sistem operasi seperti Windows, Linux/Unix, Mac OS X, OS/2, Amiga, Palm Handhelds dan telepon genggam Nokia. saat ini Python juga telah di porting kedalam mesin virtual Java dan .NET.

Python didistribusikan dibawah lisensi OpenSource yang disetujui OSI (OpenSource Initiatives), sehingga Python bebas digunakan, gratis digunakan, bahkan untuk produk-produk komersil. Yayasan Perangkat Lunak Python - Python Software Foundation (PSF) memegang dan melindungi hak atas kekayaan intelektual dibawah Python, tertuang dalam konferensi PyCon, serta mendanai proyek-proyek pada komunitas Python.

\section{MySql}

MySQL adalah salah satu aplikasi RDBMS (Relational Database Management System). Aplikasi yang digunakan untuk menyimpan data walaupun dapat digunakan file teks sebagai media penyimpanan data, namun aplikasi database ini memiliki beberapa kelebihan. Akses data yang lebih cepat adalah salah satunya. MySQL sudah dikembangkan sejak akhir tahun 70-an dan baru tahun 1996 tersedia untuk publik. MySQL merupakan salah satu aplikasi Open Source. Seperti database server lainnya, MySQL dapat digunakan oleh multi user. Setiap user memiliki account yang dapat dipakai untuk mengakses MySQL server. MySQL menggunakan bahasa standar database, yaitu SQL (Structured Query Language). Python sangat mendukung database ini. Semua fungsi untuk akses ke MySQL sudah terintegrasi ke dalam engine Python dan Object Relational Mappers (ORMs) sebagai library yang memudahkan dalam membangun sistem karena library tersebut meng-otomatisasi kode berhubungan antar tabel database[6].

\section{Kotlin}

Kotlin merupakan

Bahasa

Pemrograman modern yang bersifat staticallytyped yang dapat di jalankan di atas platform Java Virtual Machine (JVM). Kotlin juga dapat di kompilasi (compile) ke dalam bentuk JavaScript. JetBrains selain Kotlin ini yang juga mengembangkan salah satu tools pemrograman (IDE) yang saat ini di adopsi oleh google untuk di gunakan

Sistem Pengaduan Masyarakat dan Tindak Lanjut Terintegrasi Layanan Publik Menuju Percepatan E-Government (Studi Kasus Provinsi Sulawesi Tenggara) 
sebagai tools pengembangan aplikasi di Android (Android Studio).

\section{ANALISA DAN PERANCANGAN SISTEM}
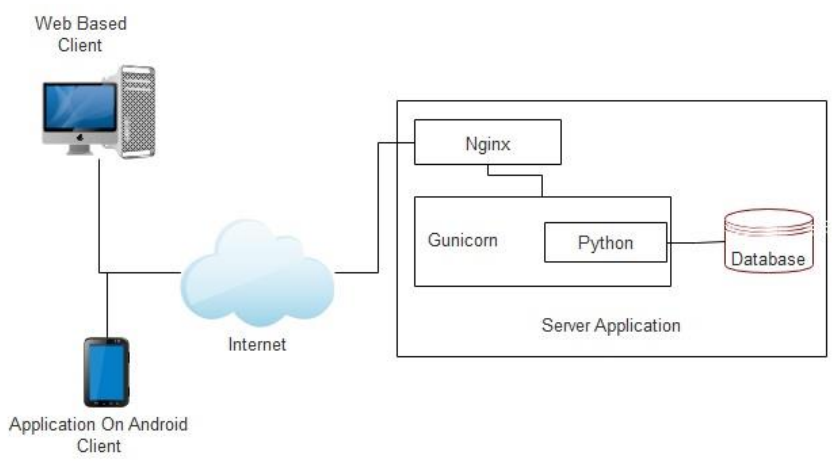

Gambar 1. Skema Rancangan Sistem

A. Pengguna Sistem

Sistem lapor ini memiliki 5 (lima) aktor (user) yakni :

1) Masyarakat Pengguna Belum terdaftar

- Melihat Laporan (melalui Web)

- Melihat Informasi terkait FLLAJ

2) Masyarakat Pengguna Sudah Terdaftar

-Mengunggah Laporan

-Memperoleh notifikasi proses laporan

-Memperoleh Informasi

-Melakukan Komentar terhadap laporan orang lain

3) Admin Forum

-Menulis Informasi

- Validasi Laporan

-Membuat Kategori Laporan

-membuat user instansi pendukung Forum

-penugasan laporan sesuai kategori dan instansi

-melihat rangkuman status laporan

4) User Instansi

-Menindaklanjuti Laporan dari verifikator

-melaporkan hasil tindak lanjutnya

-melihat rangkuman status laporan

5) Operator verifikator

-Menindak lanjuti Keluhan

-Melaporkan hasil tindak lanjutnya

Sehingga dari 5 (lima) aktor/user dan fungsi tersebut kami dapat mendesain database untuk sistem lapor sebagai berikut :

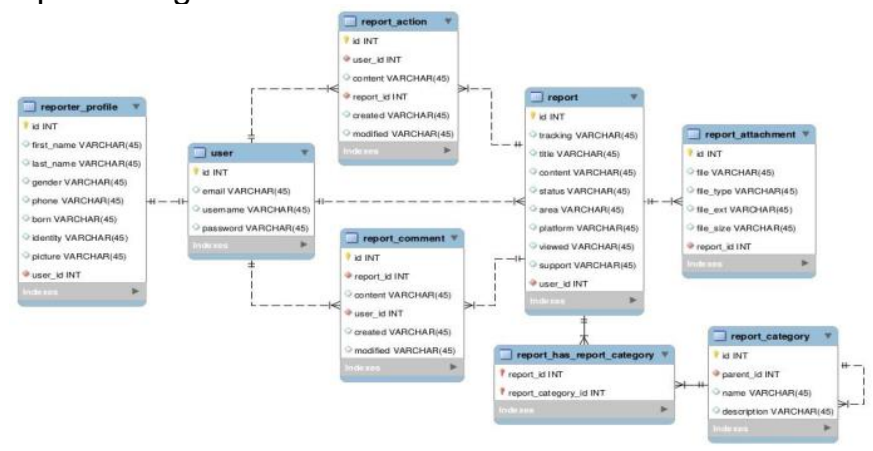

Gambar 2. Database Sistem Lapor

\section{B. Infrastruktur Teknologi Informasi}

Infrastruktur Teknologi Informasi memenuhi kriteria sebagai berikut:

1) Mempunyai ketersediaan yang tinggi (high availability)

2) Mempunyai kinerja yang tinggi (high performance).

3) Mendukung akses multi-user (minimal dapat diakses 100 concurrent user) tanpa timbul gangguan.

4) Memiliki tingkat keamanan yang tinggi

C. Sistem Aplikasi

Sistem Aplikasi dibangun dengan spesifikasi sebagai berikut:

1) Untuk Website Menggunakan bootstrap framework dan menggunakan responsive design

2) Website Mampu membuat halaman sebagai menu navigasi secara dinamis

3) Database menggunakan MYSQL.

4) Untuk Aplikasi Mobile menggunakan pemrograman native

5) Komunikasi dengan aplikasi lain menggunakan REST API.

6) Aplikasi mobile Android terdaftar di google play

Fungsi-fungsi yang akan dikomputerisasi sebagai berikut:

1. Pembuatan Fitur Website:

a) Beranda

b) Profil FLLAJ, Struktur Organisasi,

c) Berita, agenda kegiatan,

d) Media (Foto dan Video)

e) Halaman Aspirasi dan Pelaporan

f) Dokumen

g) Kontak

h) Halaman menu lainnya yang dinamis untuk di tambahkan

i) Dashboard Kontrol website:

-CRUD Artikel

-CRUD Kategori Artikel

-CRUD Page/Halaman

-Navigasi menu

-Modul Media Foto dan Video

-Modul Carousel

-Modul Link terkait

-Menu Titel, icon Website dan Kontak Info

2. Pembuatan Aplikasi Berbasis Web Pengaduan Masyarakat untuk Admin

a.Dashboard Statistik

b.List Notifikasi

c. CRUD Instansi

d. CRUD User (Pelapor, Instansi, Verifikator dan

Admin)

e) Halaman List Pelaporan

f) CRUD Kategori pelaporan

g)Settting version Mobile

h) Kirim Informasi Event ke semua User

3. Pembuatan Aplikasi Mobile Pengaduan Masyarakat

Sistem Pengaduan Masyarakat dan Tindak Lanjut Terintegrasi Layanan Publik Menuju Percepatan E-Government (Studi Kasus Provinsi Sulawesi Tenggara) 

a) List Laporan
b) Buat Laporan
c) Notifikasi Laporan
d) Akun (edit Profil dan Password)
e) Support login dengan Email/ID Google
f) Support GPS lokasi pelaporan
g) Support kirim foto / gambar dari camera Android
h) Terdaftar di Google Play
i) Info Event support dengan gambar dan lokasi GPS
j) List Berita/artikel dari website

4. Pembuatan Aplikasi Mobile Pengaduan untuk Verifikator

a) List Laporan berdasarkan Status (Baru, diterima, Proses dan Selesai)

b) Info Event support dengan gambar dan lokasi GPS

c) List Berita/artikel dari website

d) Notifikasi Laporan

e) Akun (Edit, Profil dan Password)

f) melakukan disposisi laporan dan merubah status laporan

\section{IMPLEMENTASI SISTEM}

Setelah melalui tahap Analisa dan perancangan system maka selanjutnya adalah pembuatan system yang di mulai dari pembuatan basis data. Adapun Basis data yang dibuat di beri nama garbarata_db yang terdiri dari 37 tabel seperti terlihat dibawah ini:
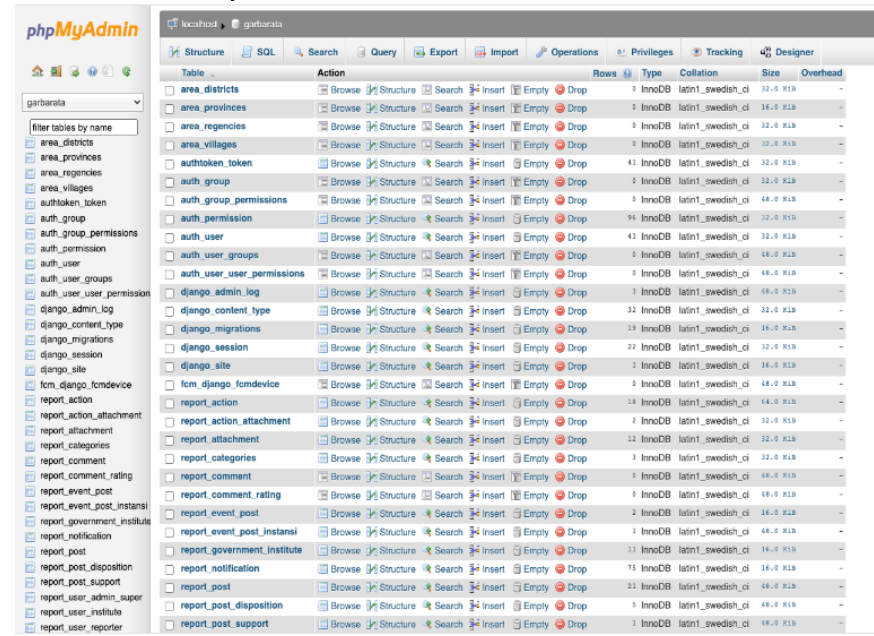

\section{Gambar 3. Database Garbarata}

Melalui proses pengkodingan maka seluruh fitur yang terdapat tampilan web yang telah didesain akan terkoordinasi/dlink-kan dengan basis data 'garbarata_db' yang akan membetik suatu system informasi pengaduan. Adapun hasil tampilan halamanhalaman web dapat dilihat di bawah ini.

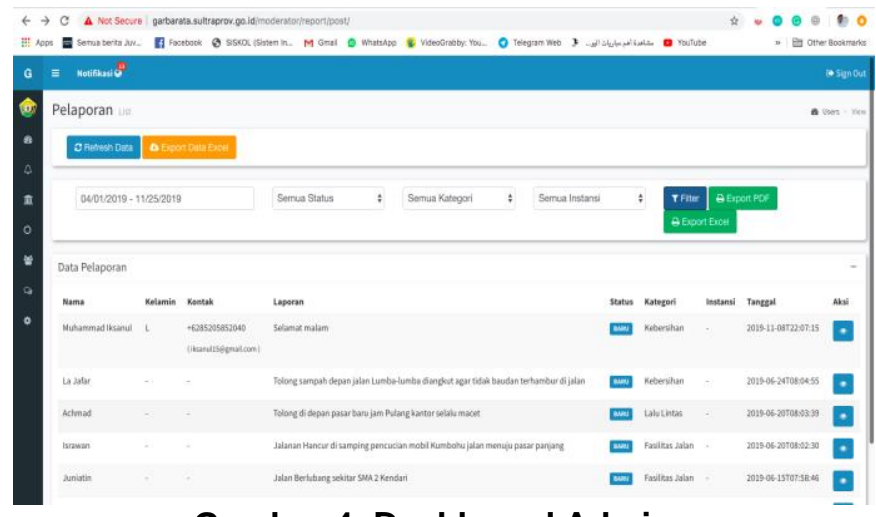

Gambar 4. Dashboard Admin

Sedangkan desain tampilan awal saat login app Garbarata bisa dilihat pada gambar 5 berikut.
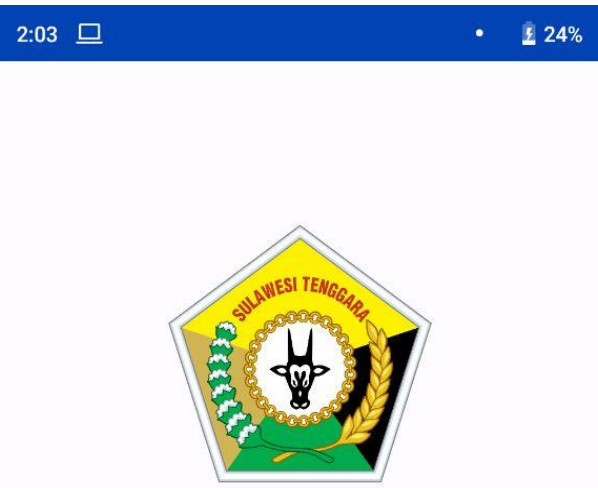

GARBARATA

Pelayanan Laporan Masyarakat

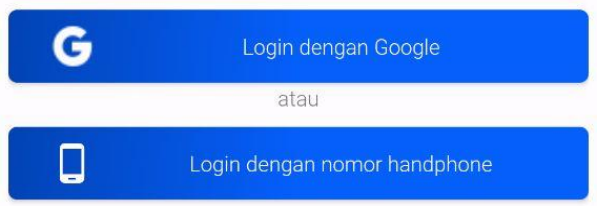

Gambar 5. Tampilan Login

Setelah login akan muncul menu laporan yang sudah diajukan dan menunggu status sedang diproses seperti pada gambar 6 berikut. 


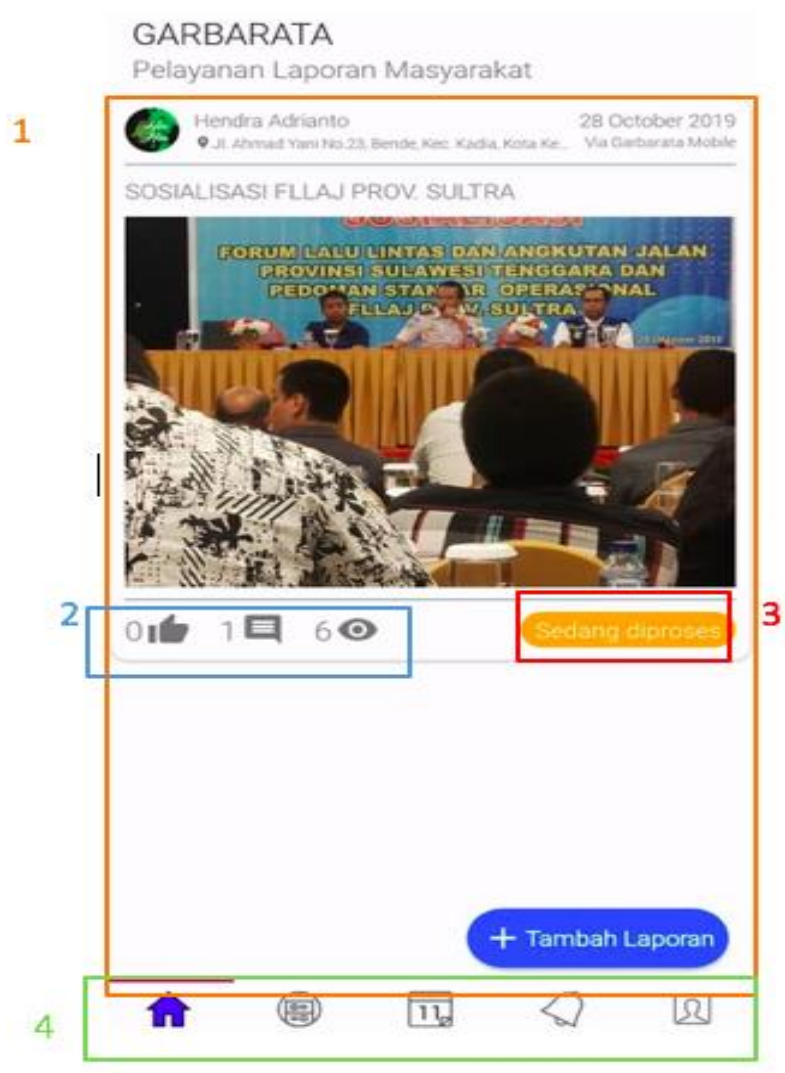

Gambar 6. Tampilan Garbarata

\section{KESIMPULAN}

Setelah melalui berbagai tahapan perencanaan Sistem ini di Provinsi Sulawesi Tenggara berbasis Web dan Android. Semua Pengaduan dari masyarakat di layani melalui aplikasi dan dtindak lanjuti secara terintegrasi dari seluruh instansi pemerintah yang terlibat.

Sehingga pelayanan kepada masyarakat berbasis teknologi ini mempercepat implementasi E-Government.

Kesimpulan yang didapat dalam pembahasan penelitian ini adalah sebagai berikut :

1. Pengguna Sistem terdiri dari 5 role user yakni : Masyarakat Pengguna Belum terdaftar, Masyarakat Pengguna Sudah Terdaftar, Admin Forum, User Instansi, dan Operator verifikator

2. Dengan dikembangkannya system ini di harapkan pelayanan terhadap pengaduan masyarakat lebih cepat karena realtime

3. Sistem ini merupakan sarana atau koordinasi sekuruh instansi pemerintah Provinsi Sulawesi Tenggara.

\section{DAFTAR PUSTAKA}

[1] Santosa, Insap. IR, Interaksi Manusia dan Komputer, Andi Yogyakarta, 1998
[2] Pressman, Roger S, Software Engineering : A Practisioner Approach Fourth Edition, MC Grow Hill, 1997.

[3] Tim Penelitian dan Pengembangan Wahana Komputer, Pembuatan Program Sistem Informasi Akademik Berbasis ASP, Salemba Infotek, Jakarta, 2003.

[4] Brian K. Williams, Stacey C. Sawyer, Using Information Technology: A Practical Introduction to Computers \& Communications, The McGrawHill, ISBN 979-763-817-0, 2007 [5] Kadir, Abdul, Pengenalan Sistem Informasi. ANDI Offset. Yogyakarta.

[6] Madcoms Madiun, PHP \& MySQL, Andi, Yogyakarta, ISBN 978-979- 29-0610-3, 2008 